\title{
T Cell Integrin Overexpression as a Model of Murine Autoimmunity
}

\author{
Raymond L. Yung ${ }^{2 *}$, Donna Ray ${ }^{1}, \mathrm{Ru}$ Ran Mo' and Jun Chen ${ }^{1}$ \\ 'Department of Internal Medicine, University of Michigan, Ann Arbor, MI 48109-0940, USA.
}

${ }^{2}$ Divisions of Geriatrics and Rheumatology, Department of Internal Medicine, University of Michigan, 1500 East Medical Center Drive, Ann Arbor, MI 48109-0940, USA.

"To whom correspondence should be addressed: Raymond L. Yung, Divisions of Geriatrics and Rheumatology, Department of Internal Medicine, University of Michigan, 1500 East Medical Center Drive, Ann Arbor, MI 48109-0940, USA. Phone: 734-764-2266; Fax: 734-936-9220; Email: ryung@umich.edu

Submitted: August 6, 2003; Revised: October 9, 2003; Accepted: October 10, 2003; Published: October 24, 2003

Indexing terms: Integrins; DNA methylation.

\begin{abstract}
Integrin adhesion molecules have important adhesion and signaling functions. They also play a central role in the pathogenesis of many autoimmune diseases. Over the past few years we have described a $\mathrm{T}$ cell adoptive transfer model to investigate the role of $\mathrm{T}$ cell integrin adhesion molecules in the development of autoimmunity. This report summarizes the methods we used in establishing this murine model. By treating murine CD4+ T cells with DNA hypomethylating agents and by transfection we were able to test the in vitro effects of integrin overexpression on $\mathrm{T}$ cell autoreactive proliferation, cytotoxicity, adhesion and trafficking. Furthermore, we showed that the ability to induce in vivo autoimmunity may be unique to the integrin lymphocyte function associated antigen-1 (LFA-1).
\end{abstract}

\section{INTRODUCTION}

Integrin adhesion molecules are a family of heterodimers formed by two covalently linked $\alpha$ and $\beta$ glycoprotein chains $(1,2)$. Selected integrins are expressed on T cells. These include LFA-1 (CD11a/CD18, $\alpha \mathrm{L} \beta 2$ ), very late activation antigen-4 (VLA-4, CD49d/CD29, $\alpha 4 \beta 1)$, lymphocyte Peyer's patch adhesion molecule-1 (LPAM-1, CD49d/ $\beta 7, \quad \alpha 4 \beta 7$ ) and $\alpha v \beta 3$ (CD51/CD61). The integrins are best known for their central role in the arrest and transmigration of leukocytes to sites of inflammation and immune response. In addition, they also act as co-stimulatory molecules involved in the bi-directional signaling into and out of T cells $(3,4)$. Interactions between integrins and their receptor ligands have important consequences and can lead to $\mathrm{T}$ cell tyrosine phosphorylation $(5)$, cytokine production $(6,7)$, cellular proliferation $(6,7)$ or cell death $(8)$.
$\mathrm{T}$ cell integrins may also play a role in the pathogenesis of autoimmune diseases. For example, patients with lupus have $\mathrm{T}$ cell subsets that overexpress LFA-1. These LFA-1overexpressing $\mathrm{T}$ cells are also autoreactive and will proliferate in response to autologous antigen presenting cells alone without specific antigen or mitogen $(9,10)$. Interestingly, the subset of lupus patients with vasculitis also has $T$ cells that overexpress the CD49d integrin (10). However, the pathogenic significance of these autoreactive $\mathrm{T}$ cells is unclear. We recently investigated the consequence of $\mathrm{T}$ cell integrin overexpression by drug treatment and transfection. We showed that LFA-1 overexpression correlates to the development of in vitro autoreactivity and in vivo autoimmunity. In contrast, although CD49d overexpression resulted in similar $\mathrm{T}$ cell autoreactive proliferation, these cells were incapable of inducing in vivo autoimmunity. The methods we used and the results are summarized below (Table 1). 


\section{MATERIALS AND METHODS}

\section{Mice}

$\mathrm{AKR} / \mathrm{J}$ and B10.A mice were purchased from Jackson laboratory (Bar Harbor, ME) at 6-8 weeks of age. Older AKR mice were not used as these mice have a high incidence of lymphoma by the time they are 12 months old (11). Oophorectomy, orchiectomy and splenectomy were performed on $\mathrm{AKR} / \mathrm{J}$ mice at Jackson laboratory. The mice were allowed to recover for at least 4 weeks before they were used for any of the experiments. For the hormone replacement experiments, $\beta$-estradiol (60-day release, $0.36 \mathrm{mg} /$ pellet achieving blood level of $150-200 \mathrm{pg} / \mathrm{ml}$ ), progesterone (60-day release, $25 \mathrm{mg} /$ pellet achieving blood level of $15-20 \mathrm{ng} / \mathrm{ml}$ ) or placebo pellets (all from Innovative Research of America, Sarasota, FL) were implanted under the skin on the lateral side of the neck of the animals. Experiments were done on the mice 2-3 weeks after the pellets had been implanted.

\section{T cell culture}

D10.G4.1, a conalbumin-reactive cloned T-helper (Th) 2 cell line, was obtained from the American Type Culture Collection (Rockville, MD). The cells were cultured in Click's medium (Sigma, MO) supplemented with 10\% fetal calf serum (FCS), $40 \%$ interleukin (IL)-2 containing conditioned media, $2 \mathrm{mM}$ glutamine, $100 \mathrm{IU} / \mathrm{ml}$ penicillin, $100 \mu \mathrm{g} / \mathrm{ml}$ streptomycin, and 5 x $10^{-5} \mathrm{M} 2$-mercaptoethanol. The cells are maintained by weekly challenging with irradiated (3,000R) AKR/J splenocytes and conalbumin $(100 \mu \mathrm{g} / \mathrm{ml})$. Because of a report (12) that the D10 line may contain an autoreactive subset we first subcloned the cells by limiting dilution at 0.2 cells/well. In addition, we find that chronic culture of D10 cells can also result in the emergence of an autoreactive line. We therefore checked for $\mathrm{T}$ cell autoreactivity by proliferation assay every 4-6 weeks. We also did not use D10 cells that have been cultured for more than 2-3 months. AE7 cells, a pigeon cytochrome C-reactive Th1 line was obtained from Dr. Ronald Swartz (National Institute of Health) and cultured in the same media as D10 cells except the Click's media was replaced with 50\% Click's and 50\% RPMI media. The AE7 cells were challenged weekly with irradiated B10.A splenocytes and pigeon cytochrome C $(100 \mu \mathrm{g} / \mathrm{ml})$.

\section{Primary endothelial cell culture}

Microvascular endothelial cells were isolated according to a previously published protocol (13). Mouse ears from 3-4 weeks old female AKR mice were split into two and incubated in $0.5 \%$ Dispase II (Boehringer Mannheim, Germany) in phosphate buffered solution (PBS) (Gibco BRL) at $37^{\circ} \mathrm{C}$ for 1 hour. The dermal layer was then dissected away from the epidermal layer under a dissecting microscope. Microvascular endothelial cells were scraped off from the dermal layer using the blunt end of a scalpel. The cells were then allowed to grow on $1 \%$ gelatincoated sterile petri dish in RPMI (Gibco BRL) media with
Fungizone $(260 \mathrm{mg} / \mathrm{ml})$ (Gibco BRL), endothelial cell growth supplement (Collaborative Biomed, Bedford, MA), and FCS. Passage 2 (P2) cells on day 10 were used. Identity of the endothelial cells was confirmed by their cobblestone morphology, uptake of fluorescent-labeled acetylated low density lipoprotein (1,1'-diotadecyl-3,3,3',3'-tetramethyl-indo-carbocyanine perchlorate, DiI-Ac-LDL), expression of Von Willibrand factor (VWF) and CD34.

\section{Drug treatment protocols}

In mammalian cells, methylation of DNA helps stabilize chromatin in an inactive configuration and inhibits gene transcription (14-16). A number of DNA hypomethylating agents are capable of inducing T cell LFA-1 overexpression and major histocompatibility complex (MHC)-specific autoreactive proliferation, most likely via inhibition of the DNA methyltransferase 1 (Dnmt1) enzyme (17-20). Because dividing T cells are required, the cells were treated 24 hours after challenging with 1-2.5 $\mu \mathrm{M}$ 5-azacytidine, $25-50 \mu \mathrm{M}$ procainamde, $25-50 \mu \mathrm{M}$ $N$-acetylprocainamde, $5-50 \mu \mathrm{M}$ hydralazine or $5-50 \mu \mathrm{M}$ phthalazine (all from Sigma-Aldrich, MO).

\section{Adoptive transfer protocol}

6 weeks old AKR and B10.A mice were used for the D10 and AE7 cells adoptive transfer experiments respectively. The protocol we used is based on the CD4+ T cell adoptive transfer murine chronic-graft-versus-host model (21, 22). The drugtreated D10 and AE7 cells and the transfectants were washed, dead cells removed by centrifugation through Lympholyte $\mathrm{M}$ (Hornby, Ontario, CA). $5 \times 10^{6}$ viable cells were suspended in 0.1 $\mathrm{ml}$ sterile PBS and injected into the tail vein of syngeneic mice, using a 26 gauge needle every two weeks for a total of 6 injections. The rationale for repeated adoptive transfers derives from the observation that drug-induced autoreactivity is selflimited (19). 4 weeks after the last injection the mice were euthanized and studied for the development of serologic and histologic evidence of autoimmunity.

\section{Generation of pSub2-CD18 and pSub2-CD49d constructs}

The mammalian expression vector pSub2 containing the neomycin-resistant cassette was donated by Dr. Mike Clarke (University of Michigan, MI). The pSub2 polylinker site was cleaved with EcoRV, and EcoR1(NotI) adapters (GIBCO BRL, Gaithersburg, MD) ligated to the blunt ends. The $2.8 \mathrm{~kb}$ murine CD18 cDNA and $4 \mathrm{~kb}$ murine CD49d cDNA plasmids were donated by Dr. Raymond Wilson (Baylor College of Medicine, TX) and Dr. Irving Weissman (Stanford University, CA) respectively. Sense and anti-sense CD18/pSub2 and CD $49 \mathrm{~d} / \mathrm{pSub} 2$ constructs were then made by cloning the fragments into the NotI adaptor sites. The constructs were linearized by digestion with ScaI and D10 cells transfected by 
electroporation ( $250 \mathrm{~V}$ and $960 \mathrm{mu}$ F). Stable transfectants were selected and maintained by culturing in media containing 250 $\mu \mathrm{g} / \mathrm{ml}$ Geneticin (G418) (GIBCO BRL). Finally, the transfectants were subcloned by limiting dilution at $\leq 0.2$ cells/well.

\section{Southern blot analysis}

Southern blot analyses of the transfectants and control D10 cells were performed. Briefly, 20-30 $\mu \mathrm{g}$ of genomic DNA from the cells was digested overnight with NotI restriction enzyme at $37^{\circ} \mathrm{C}$ and resolved by $1 \%$ agarose gel before being transferred to nylon membranes (MagnaGraph; Micro Separations, Inc., Westborough, MA). The filters were hybridized with ${ }^{32} \mathrm{P}$-labeled (Genius system; Boehringer Mannheim) full length CD18 or CD49d cDNA, excised from pSub2 with Not1, and exposed to $\mathrm{x}$-ray film.

\section{Flow cytometric analysis}

Transfectants and control cells were allowed to react with monoclonal antibodies (mAbs) conjugated with FITC or PE including anti-CD3, -T cell receptor (TCR), -CD18, -CD28, -

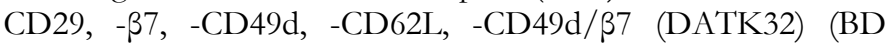
PharMingen) and goat anti-mouse immunoglobulin (Ig) (Coulter Corp., Hialeah, FL) and analyzed by a Coulter ELITE flow cytometer.

\section{Proliferation assays}

$10^{4}$ drug-treated D10 cells, AE7 cells or transfectants were cocultured with $10^{3}-10^{4}$ irradiated syngeneic splenocytes (antigen presenting cells) with or without $100 \mu \mathrm{g} / \mathrm{ml}$ conalbumin (D10) or pigeon cytochrome C (AE7) for 4 days in culture media lacking IL-2 using round bottom microtiter plates. Proliferation was measured by ${ }^{3} \mathrm{H}$-labeled TdR incorporation. For the inhibition studies, the $\mathrm{T}$ cells were preincubated with mAbs against $\mathrm{CD} 49 \mathrm{~d}$, CD29, $\beta 7, \mathrm{CD} 18$, Iak, Iab/d or control Ig antibodies for 30 minutes at $37^{\circ} \mathrm{C}$, washed $\times 3$ with RPMI, before co-culturing with the antigen presenting cells.

\section{Cytotoxicity assays}

Peritoneal macrophages were obtained by injecting $2 \mathrm{ml}$ thioglycolate solution into the peritoneal cavity of 6 weeks old AKR or B10.A mice. Two days later the cells were collected by washing the peritoneal cavity with $10 \mathrm{ml}$ PBS. The cells were then labeled with $100 \mu \mathrm{Ci} \quad\left[{ }^{51} \mathrm{Cr}\right]-\mathrm{Na}_{2} \mathrm{Cr}_{2} \mathrm{O}_{7}$ (New England Nuclear, Boston, MA) $/ 10^{7}$ cells in $1 \mathrm{ml}$ solution. Cytotoxicity assays were done by co-culturing the drug-treated or transfected D10 cells with the ${ }^{51} \mathrm{CR}$-labeled peritoneal macrophages as target cells for 18 hours in culture media lacking IL-2. The effector:target cell ratio used was between 5-10:1. Percent cytotoxicity was calculated as [(experimental - background release)/(total incorporation - background release)] X 100.

\section{ELISA assays}

Serum immunoglobulins and autoantibodies were measured using Immulon 4 plates (Dynatech Laboratories) coated with $2.5 \mu \mathrm{g}$ antimouse IgG, IgM (Sigma), purified ssDNA (Sigma) or dsDNA (cesium chloride-purified KS+-SV2CAT plasmid) in $100 \mu \mathrm{l} 0.01 \mathrm{M}$ PBS, $\mathrm{pH} 7.4$ for 18 hours at $4^{\circ} \mathrm{C}$. The plates were washed $\mathrm{x} 3$ with PBS containing $0.05 \%$ Tween 20, then $200 \mu$ l of PBS supplemented with $3 \%$ BSA, $0.1 \%$ gelatin and $0.05 \%$ Tween 20 were added and incubated 2 hours at room temperature. Samples or Ig standards were diluted to the desired concentrations in PBS containing 3\% BSA and $0.1 \%$ gelatin, added to the wells and incubated 18 hours at $4^{\circ} \mathrm{C}$, then washed x 3. $100 \mu$ horseradish peroxidase (HRP)-conjugated goat anti-mouse Ig was added at a final dilution of 1:2500 in PBS containing 0.05\% Tween 20 and incubated for 2 hours at room temperature. Pooled sera from 6 month old female NZB/NZW mice or 5 month old female $\mathrm{MRL} / \mathrm{hr}$ mice were used as positive controls. The plates were developed using Sigma Fast tablets (Sigma) according to the manufacturer's instructions.

\section{Static and flow adhesion assays}

Endothelial cells were grown to $90 \%$ confluence in 1\% gelatincoated 24-well plate (Costar). Transfectants and control D10 cells were labeled with ${ }^{51} \mathrm{Cr}$ by culturing $10 \times 10^{6}$ cells with $100 \mu \mathrm{Ci}$ $\left[{ }^{51} \mathrm{Cr}\right]-\mathrm{Na}_{2} \mathrm{Cr}_{2} \mathrm{O}_{7}$ (New England Nuclear, Boston, $\mathrm{MA}$ ) in $1 \mathrm{ml}$ at $37^{\circ} \mathrm{C}$ for 1 hour. The cells were washed 3 times with RPMI 1640 (Gibco, Grand Island, NY). The ${ }^{51} \mathrm{Cr}$-labeled D10 cells were then allowed to adhere to the endothelial cell monolayer for 30 mins at $37^{\circ} \mathrm{C}$. The non-adhered cells were removed by washing $\mathrm{x} 3$ with RPMI 1640. The adhered cells were then lyzed with NP-40, and radioactivity counted by a beta counter. For the functional blockade experiments, the CD49d-transfected D10 cells were preincubated with either anti-CD49d or control Ig antibodies for 30 minutes at $37^{\circ} \mathrm{C}$, washed $\mathrm{x} 3$ with RPMI, before adhesion to the endothelial cells.

The parallel-plate flow chamber used in the flow adhesion assays has been described previously in detail $(23,24)$. Briefly, the chamber is composed of two stainless steel plates separated by a Silastic gasket $(250 \mu \mathrm{m}$ thickness, Dow Corning). The flow channel was formed by removal of a $5.0 \times 50.0 \mathrm{~mm}$ rectangular section from the Silastic gasket. Defined levels of flow were applied to the endothelial cell monolayer by drawing the perfusion medium (PBS containing $0.7 \mathrm{mmol} / \mathrm{L} \mathrm{Ca}^{2+}, 0.7$ $\mathrm{mmol} / \mathrm{L} \mathrm{Mg}^{2+}$, and $0.2 \%$ fetal calf serum) through the channel using a syringe pump (model 44, Harvard Apparatus). A copper heating plate with two electrical heating cartridges (SC12-1, Hotwatt) was mounted on the top of the chamber to maintain temperature at $37^{\circ} \mathrm{C}$. The channel flow can be approximated as two-dimentional fully developed laminar flow with a simple parabolic velocity profile, since the channel height is a linear function of the volume flow rate through the channel. Microvascular endothelial monolayers on coverslips were stimulated with TNF- $\alpha(2.5 \mathrm{ng} / \mathrm{ml})$ for 16 hours at $37^{\circ} \mathrm{C}$, 
positioned in the flow chamber, and mounted on an inverted microscope equipped with $10 \mathrm{x}$ and $40 \mathrm{x}$ phase contrast objectives. A circular glass window in the top plate allowed direct examination of the monolayer during the experiment. The monolayer was perfused for 5 to 10 minutes with perfusion medium to verify that the monolayer was confluent and intact. $10^{6}$ cells $/ \mathrm{ml}$ perfusion medium of the CD49d-transfected and untransfected D10 cells were drawn through the chamber at 2.0 dyne $/ \mathrm{cm}^{2}$ for 5 minutes, then decreased to 0.2 dyne $/ \mathrm{cm}^{2}$ for 5 minutes. Leukocyte adhesion was determined by counting the number of $\mathrm{T}$ cells in 20 randomly selected high-power microscope fields during the final minute at each level of flow.

\section{Western blots}

D10 cells and transfectants were stimulated with anti-CD3 (10 $\mathrm{mg} / \mathrm{ml}$ ) for 10 minutes and crosslinked with goat anti-rat IgG. Proteins from the cells were resolved on $10 \%$ SDSpolyacrylamide gel and transferred to nitrocellulose-1 membrane. The membrane was then incubated with horse radish peroxidase (HRP) conjugated anti-phosphotyrosine antibody (Chemicon International, CA) and anti-mouse IgG (Chemicon International). Detection was performed using the ECL system (Amersham Life Science) according to the manufacturer's instructions. The membrane was stripped and probed with control anti- $\beta$-actin antibodies (Chemicon International).

\section{Measurement of intracellular calcium}

D10 cells and transfectants were suspended in RPMI, 2\% FBS, $25 \mathrm{mM}$ HEPES (pH 7.4) and loaded with $1.5 \mathrm{mM}$ Indo-1 for 45 minutes at $37^{\circ} \mathrm{C}$ in the dark, then washed twice with DMEM, $2 \%$ FBS and resuspended in RPMI, 2\% FBS, $25 \mathrm{mM} \mathrm{HEPES} \mathrm{(pH}$ 7.4) and stored in the dark at room temperature until 1 hour before analysis. Cells were then diluted to $1 \times 10^{6} / \mathrm{ml}$ with RPMI, $2 \% \mathrm{FBS}, 25 \mathrm{mM} \mathrm{HEPES}$, and allowed to equilibrate at $37^{\circ} \mathrm{C}$, in the dark for 30-60 minutes. Cells were then incubated with 10 $\mu \mathrm{g} / \mathrm{ml}$ of the indicated $\mathrm{mAb}$ for 1-5 minutes and then crosslinked with anti-rat $\operatorname{IgG}$, and calcium release immediately analyzed by flow cytometry. Ionomycin $(1 \mu \mathrm{g} / \mathrm{ml})$ was used as a positive control.

\section{In vivo T cell splenic homing}

Drug-treated and transfected D10 cells were labeled with CellTracker $^{\mathrm{TM}}$ Green 5-chloromethylfluorescein diacetate (CMFDA) (Molecular Probes, Eugene, OR), carboxyfluorescein diacetate, succinimidyl ester (CDFA-SE) (Molecular Probes) or PKH26 green fluorochrome (Sigma, St. Louis, MO) using the protocols provided by the manufacturers. Viability of the cells was determined by trypan blue exclusion and was similar in the labeled and unlabeled cells. 5-10 x $10^{6}$ labeled cells were injected intravenously via the tail vein, and the mice were euthanized 24 hours later. Labeled D10 cells were detected by staining splenocytes with FITC or phycoerythrin (PE)-conjugated antiCD4, then enumerating cells expressing both CD4 and CMFDA or CDFA-SE with a Coulter ELITE flow cytometer. For controls, D10 homing to the lungs was also determined. Briefly, the lungs were perfused in situ using normal saline to clear the pulmonary vasculature, and then the cells in the airways and alveolar spaces were collected by bronchoalveolar lavage. The lavaged lungs were then dissected free of extrapleural lymphatic tissue and finely minced and enzymatically digested (collagenase plus DNase). The cells were then washed and the D10 cells enumerated as for the spleen cells.

\section{RESULTS AND DISCUSSION}

\section{Characterization of drug-treated and CD18, CD49d transfectants}

Previous works using flow cytometric staining and 2-dimensional protein gel analysis have shown that expression of only a few $\mathrm{T}$ cell surface antigens, including LFA-1, are changed following treatment with DNA hypomethylating agents (9). To directly test the functional consequence of T cell LFA-1 overexpression, a murine CD18 construct (CD18/pSub2) was transfected into D10 cell. The stably transfected D10 cells exhibited a 10-fold increase in LFA-1 expression (both the CD11a and CD18 chain) (25). To determine if overexpression of other $\beta$ integrins has similar functional consequence we substituted the CD18 cDNA with a murine CD49d cDNA and transfected the construct (CD49d/pSub2) into D10 cells. The CD49d D10 transfectants also had a roughly 10-fold increase in CD49d surface expression (26). Interestingly, and for unclear reason, the corresponding $\beta 7$ but not $\beta 1$ (CD29) chain was similarly increased in the CD49d transfected D10 clones tested (Fig. 1). Flow analyses confirmed that upregulation of CD49d did not affect CD18, CD28, CD4, CD62L or T-cell receptor expression.

\section{Murine CD4+ cells become autoreactive following treatments with DNA hypomethylating agents or transfection with CD18, CD49d}

To establish a murine model of drug-induced autoimmunity, we first determined if murine CD4+ $\mathrm{T}$ cells respond to DNA demethylating agents, including 5-azacytidine, procainamide and hydralazine, in a similar way as their human counterparts. Our results showed that drug-treated murine polyclonal (28), cloned Th1 (AE7) (29) and cloned Th2 (D10) (25, 28-30) CD4+ T cells also overexpressed LFA-1 and proliferated to normally subthreshold antigen stimulation in the presence of self MHC class II molecules. In contrast $N$-acetylprocainamide (the metabolites of procainamide) and phthalazine (the parent compound of hydralazine that lacks the hydrazine side chain), which do not induce lupus, were much less potent in their ability to induce T cell autoreactivity (31). Similarly, D10 cells made to overexpress LFA-1 or CD49d demonstrated autoreactive proliferation against syngeneic antigen presenting cells (Fig. 2). 


\section{Overexpression of CD18, but not CD49d, induces macrophage apoptosis}

Interestingly, the LFA-1 overexpressing $\mathrm{T}$ cells also killed syngeneic macrophages by apoptosis (27-29), likely involving the TNF-related apoptosis-inducing ligand (TRAIL, Apo2 ligand) and TNF-like weak inducer of apoptosis (TWEAK, Apo3 ligand) (32). In contrast, although CD49d transfected D10 cells exhibited similar proliferation in response to antigen presenting cells as CD18 transfected cells they were unable to induce apoptosis in the target cells. This is consistent with reports that LFA-1, but not CD49d, has an important role in modulating T cell cytotoxic functions (33-36). Increased monocyte apoptosis has been reported in lupus patients and it has been proposed that if this occurs in the appropriate lymphoid organ such as the spleen it may provide a source of antigenic nucleic acids that contributes to the autoimmune process in these patients (32). The lack of cytotoxicity of CD49d compared to CD18 integrin may therefore impact the ability of autoreactive $\mathrm{T}$ cells to induce autoimmune disease.

\section{Autoreactive proliferation in LFA-1 and CD49 overexpressing D10 cells is due to overstabilization of TCR-la interaction}

Potential mechanisms linking integrin overexpression to $\mathrm{T}$ cell autoreactivity include transmission of an increased costimulatory signal, overstabilization of normally low affinity TCR-MHC class II interaction, or both. A role for increased $\mathrm{T}$ cell costimulation was tested by culturing control and transfectants with anti-CD3 and anti-CD11a antibodies (37). Despite minimal calcium fluxes, increased protein tyrosine phosphorylation was observed in both CD18 and CD49d transfectants (26, 37). The proliferation response to graded amounts of these antibodies was identical in both cell lines suggesting that increased signaling alone is insufficient to cause the increased responsiveness (37). When cocultured with syngeneic macrophages the transfectants but not the control cells down-regulated TCR expression, thus demonstrating successful TCR signaling to a low affinity interaction (37).

\section{In vivo autoimmunity is induced by LFA-1 - but not CD49d-overexpressing D10 cells}

Non-irradiated syngeneic (AKR) mice receiving 5-azacytidine or procainamide treated D10 cells developed a severe immune complex glomerulonephritis, pulmonary alveolitis, central nervous system abnormalities including fibrinoid necrosis, karyorrhexis, and meningitis, and bile duct proliferation with periportal inflammatory cell infiltration resembling primary biliary cirrhosis (Fig. 3). Anti-ssDNA, anti-dsDNA, and antihistone antibodies were also found (25, 27-29). In contrast, mice receiving $N$-acetylprocainamide and phthalazine did not develop any disease (31). Similar to other lupus autoimmunity models such as the MRL/lpr and NZB/NZW mice, female mice receiving the drug-treated $\mathrm{T}$ cells also developed a more severe disease with high titers of autoantibodies than male mice (30). Additionally, splenectomized mice receiving the drug-treated D10 cells also did not develop autoantibodies or other features of autoimmune disease (30). This suggests that the ability of LFA-1 overexpressing $\mathrm{T}$ cells to induce autoimmune disease may be dependant on the ability of the transferred $\mathrm{T}$ cells to interact with immune cells in the spleen. Interestingly, AKR mice receiving the CD18 (25) but not the CD49d transfectants (26) developed autoantibodies, immune complex glomerulonephritis and pulmonary alveolitis, similar to mice receiving the drug-treated cells. Human patients with systemic lupus erythematosus have also recently been shown to have $T$ cell subsets that overexpress LFA-1 and are autoreactive $(9,10)$. Taken together, these results support a direct role of T cell LFA-1 overexpression in the induction of both human and murine autoimmunity.

\section{T cell CD49d overexpression causes increased binding to endothelial cell in vitro}

Our results showed that although both CD18 and CD49d overexpression induced $\mathrm{T}$ cell autoreactive proliferation, only the CD18 overexpressing $\mathrm{T}$ cells are capable of inducing in vivo autoimmunity. To confirm that inducing $\mathrm{T}$ cell CD49d overexpression by transfection has functional consequences, we performed both static and flow adhesion assays using control D10 and Cd49d transfectants (26). Under static condition, 4 times more CD49d transfectants were found to adhere to TNFstimulated endothelial cells compared with untransfected D10 cells $(p<0.01)$. The increased adhesion was reversed with the addition of anti-CD49d but not anti- $\beta 7$ or CD29 antibodies. Binding of CD49d transfectant under high (physiological) flow rate $\left(2.0\right.$ dyne $\left./ \mathrm{cm}^{2}\right)$ was similar to untransfected D10 cells. However, a 4-fold increase in binding to endothelial cells was observed under low flow condition $\left(0.2\right.$ dyne $\left./ \mathrm{cm}^{2}\right)(p<0.01)$. These results are consistent with the notion that $\alpha 4$ integrin is involved in the firm adhesion of leukocytes to vascular endothelial cells, and less in the initial contact or rolling stage of the interaction.

\section{Effect of LFA-1 and CD49d overexpression on in vivo $T$ cell splenic homing}

CD18 and CD49d overexpression induced T cell autoreactivity. However, only the CD18 overexpressing $\mathrm{T}$ cells are capable of inducing in vivo autoimmunity. Splenectomy also prevented the LFA-1 overexpressing cells from causing autoimmune disease. It is therefore possible that T cell CD49d overexpression may cause decreased splenic homing by directing the CD49d transfectants to mucosal or other lymphoid organs. This may in turn protect the recipients from developing autoimmune disease. We therefore examined the effect of CD18 and CD49d expression on in vivo $\mathrm{T}$ cell homing. This was initially done by injecting CMFDA-labeled control D10 cells, procainamide-treated D10 cells or CD49d- transfectants into AKR mice. The number of CD4+ CMFDA+ cells in the spleens of the recipient mice was then determined by flow cytometric analysis 24 hours later. The results showed that LFA-1 overexpressing T cells have similar 
splenic homing as control D10 cells (31). In contrast, CD49d transfectants were found to traffic to the spleen 3-4 times more than the control D10 cells $(p<0.05)$ (Fig. 4). To exclude the possibility that the observed increased CD49d splenic homing is the result of unintended differences in the number of cells given to individual animal in the adoptive transfer process, AKR mice were given an intravenous mixture of either $5 \times 10^{6}$ CFDA-SE (green)-labeled D10 cells and 5x106 PKH26 (red)-labeled CD49d transfectants, or $5 \times 10^{6}$ CFDA-SE-labeled CD49d transfectants and $5 \times 10^{6}$ PKH26-labeled D10 cells. Mice receiving the CFDASE-labeled D10 cells and PKH26-labeled CD49d transfectants were found to have significantly more CD49d transfectants in the spleen compared to those receiving the untransfected D10 cells $(\phi<0.001)$. Similarly mice receiving the PKH26-labeled D10 cells and CFDA-SE-labeled CD49d transfectants were found to have significantly increased D10/CD49d splenic homing $(\phi<$ $0.001)$. Taken together, these results showed that the differential ability of LFA-1- and CD49d-overexpressing T cells to induce in vivo autoimmunity is unrelated to their ability to traffic to the spleen.

\section{Effect of gender on $\mathrm{T}$ cell splenic homing is estrogen dependent}

Female mice had worse disease than male mice in our murine $\mathrm{T}$ cell adoptive transfer model of autoimmunity. In addition, splenectomy abrogated the autoimmune disease in mice receiving the autoreative $\mathrm{T}$ cells (30). We therefore sorted to determine if there was a difference in $\mathrm{T}$ cell splenic homing between male and female mice. Initial experiment was done by injecting CMFDAlabeled D10 cells into male and female mice and enumerating the number of CD4+CMFDA+ $\mathrm{T}$ cells in the spleen (30). The results showed a 2 to 7 fold increased $\mathrm{T}$ cell splenic homing in female compared to male mice $(\phi<0.01)$, even after correcting for gender difference in body and organ weights. We next examined the effects of hormone supplementation by implanting $17 \beta$-estradiol, progesterone or placebo pellets into oophorectomized female AKR mice. Similar splenic homing experiments were then performed using CMFDA-labeled D10 cells (38). The $17 \beta$-estradiol treated mice had a 2.5 fold increase $(p=0.043)$ in splenic homing vs control and a 3.5 fold increase $(p=0.032)$ vs progesterone, indicating that estrogen is the hormone primarily responsible for the increased splenic homing in female mice.

\section{CONCLUSIONS}

In this report we describe the methods we used to characterize this murine model of autoimmunity based on $\mathrm{T}$ cell intergrin overexpression. We showed that inducing LFA-1 overexpression by treatment with DNA demethylating agents or by transfection with either CD18 or CD49d was sufficient to induce $\mathrm{T}$ cell autoreactive proliferation in a MHC class II specific fashion. In addition we showed that CD18, but not CD49d, is involved in the killing of syngeneic macrophages. This provides a potential mechanism explaining the lack of ability of CD49d overexpressing $\mathrm{T}$ cells to induce in vivo autoimmune disease in mice compared to LFA-1 overexpressing T cells. Our works also showed that selected drugs that are known to cause lupus in humans may do so by inducing T cell DNA hypomethylation and LFA-1 overexpression. This may have implications for idiopathic lupus as well since similar findings of $\mathrm{T}$ cell DNA hypomethylation, LFA-1 overexpression and autoreactivity have been shown in lupus patients. Finally, the effects of estrogen on $\mathrm{T}$ cell splenic homing may provide a rationale for the worse clinical course of autoimmune diseases in females.

It is widely accepted that both genetic and environmental factors are important in the pathogenesis of autoimmune diseases including systemic lupus erythematosus. Unlike most of the currently available animal models of human lupus that are genetically based, the system described above represents the first murine model of environmentally-induced autoimmunity. Over 100 drugs have now been implicated in drug-induced autoimmunity and the list is growing (39). This system may potentially be used to test the ability of new drugs to induce lupus, such as in pre-clinical trials. The specific inciting agent and the cells responsible for the induction of autoimmunity are known in this model. This should allow us to dissect out the host factors that influence the expression of autoimmunity in vivo as well.

\section{ACKNOWLEDGMENTS}

This work was supported by grants to R.L.Y. from the National Institute of Health (2P60AR20557-20, 1K08AR01977-01A1, 1RO1HL61577-01. 1RO1AG020628-01A2), the American Federation for Aging Research (Paul Beeson Physician Faculty Scholar Award), and the GRECC, Ann Arbor VA Health System. R.L.Y. also wants to gratefully thank Dr. Bruce Richardson for his support and intellectual input that has been the driving force behind the works described in this manuscript.

\section{REFERENCES}

1. Springer TA. Traffic signals for lymphocyte recirculation and leukocyte emigration: the multistep paradigm. Cell 1994; 76:301-314.

2. Kilger G, Holzmann B. 1995. Molecular analysis of the physiological and pathophysiological role of $\alpha 4$-integrins. $J$ Mol Med 1995; 73:347-354.

3. Coppolino MG, Dedhar S. Bi-directional signal transduction by integrin receptors. Int J Biochem Cell Biol 2000; 32:171-188.

4. Hynes R. Integrins: bidirectional, allosteric signaling machines. Cell 2002; 110:673-687.

5. Nojima Y, Rothstein DM, Sugita K, Schlossman SF, Morimoto C. Ligation of VLA-4 on T cells stimulates tyrosine phosphorylation of a $105-\mathrm{kD}$ protein. J Exp Med 1992; 175:1045-1053.

6. van Seventer GA, Newman W, Shimizu Y, Nutman TB, Tanaka Y, Horgan KJ, Gopal TV, Ennis E, O’Sullivan D, Grey $\mathrm{H}$, et al. Analysis of $\mathrm{T}$ cell stimulation by superantigen 
plus major histocompatibility complex class II molecules or by CD3 monoclonal antibody: costimulation by purified adhesion ligands VCAM-1, ICAM-1, but not ELAM-1. J Exp Med 1991; 174:901-913.

7. van Seventer GA., Shimizu Y, Horgan KJ, Luce GE, Webb D, Shaw S. Remote T cell co-stimulation via LFA-1/ICAM1 and CD2/LFA-3: demonstration with immobilized ligand $/ \mathrm{mAb}$ and implication in monocyte-mediated costimulation. Eur J Immunol 1991; 21:1711-1718.

8. Damle NK, Klussman K, Leytze G, Aruffo A, Linsley PS, Ledbetter JA. Costimulation with integrin ligands intercellular adhesion molecule-1 or vascular cell adhesion molecule-1 augments activation-induced death of antigenspecific CD4+ T lymphocytes. J Immunol 1993; 151:23682379.

9. Richardson BC, Strahler JR, Pivirotto TS, Quddus J, Bayliss GE, Gross LA, O'Rourke KS, Powers D, Hanash SM, Johnson MA. Phenotypic and functional similarities between 5-azacytidine-treated $\mathrm{T}$ cells and a $\mathrm{T}$ cell subset in patients with active systemic lupus erythematosus. Arthritis Rheum 1992; 35:647-662.

10. Takeuchi T, Amano K, Sekine H, Koide J, Abe T. Upregulated expression and function of integrin adhesive receptors in systemic lupus erythematosus patients with vasculitis. J Clin Invest 1993; 92:3008-3016.

11. Karpova GV, Fomina TI, Abramova EV, Bel'skaya NV, Trofimova ES, Perel'muter VM. Hemopoietic and lymphoid organs in AKR/JY mice with thymic lymphoma. Bull Exp Biol Med 2002; 134(1):69-72.

12. Saizawa MK, Hug E, Haque S, Portoles P, Suzuki S, Eichmann K. Autoreactivity of low but not of high CD4 variants of an antigen-specific, I-A-restricted mouse $\mathrm{T}$ cell clone. J Immunol 1992; 148:702-709.

13. Murphy HS, Bakotoulos N, Dame MK, Varani J, Ward PA. Heterogeneity of vascular endothelial cell: Differences in susceptibility to neutrophil mediated injury. Microvasc Res 1998; 56:203-211.

14. Yung RL, Richardson BC. Role of T cell DNA methylation in lupus. Lupus 1994; 3:487-491.

15. Richardson BC, Yung RL. The role of DNA methylation in the regulation of cell function. J Lab Clin Med 1999; 134:333340.

16. Attwood J, Yung RL, Richardson BC. DNA methylation and the regulation of gene expression. Cell Mol Life Sci 2002; 59:241-257.

17. Richardson BC, Liebling MR, Hudson JL. CD4+ cells treated with DNA methylation inhibitors induce autologous B cell differentiation. Clin Immunol Immunopathol 1990; 55:368-381.

18. Richardson BC, Powers D, Hooper F, Yung RL, O’Rourke K. Lymphocyte Function Associated Antigen-1 Overexpression and T Cell Autoreactivity. Arthritis Rheum 1994; 37:1363-1372.

19. Richardson B. Effect of an inhibitor of DNA methylation on T cells. II. 5-azacytidine induces self-reactivity in antigenspecific T4+ cells. Hum Immunol 1986; 17:456-470.

20. Cornacchia E, Golbus J, Maybaum J, Strahler J, Hanash S, Richardson B. Hydralazine and procainamide inhibit $\mathrm{T}$ cell
DNA methylation and induce autereactivity. I Immunol 1988; 140:2197-2200.

21. Gleichmann E, Van Elven EH, Van der Veen JP. A systemic lupus erythematosus (SLE)-like disease in mice induced by abnormal T-B cell cooperation. Preferential formation of autoantibodies characteristic of SLE. Eur J Immunol 1982; 12(2):152-159.

22. Pals ST, Radaszkiewicz T, Roozendaal L, Gleichmann E. Chronic progressive polyarthritis and other symptoms of collagen vascular disease induced by graft-vs-host reaction. $J$ Immunol 1985; 134(3):1475-1482.

23. Gerszten RE, Luscinskas FW, Ding HT, Dichek DA, Stoolman LM, Gimbrone Jr. MA, Rosenzweig A. Adhesion of memory lymphocytes to vascular cell adhesion molecule1-transduced human vascular endothelial cells under simulated physiological flow conditions in vitro. Circ Res 1996; 79:1205-1215.

24. Spertini O, Luscinskas FW, Kansas GS, Munro JM, Griffin JD, Gimbrone Jr. MA, and Tedder TF. Leukocyte adhesion molecule-1 (LAM-1, L-selectin) interacts with an inducible endothelial cell ligand to support leukocyte adhesion. $J$ Immunol 1991; 147:2565-2573.

25. Yung RL, Powers D, Johnson K, Amento E, Carr D, Laing T, Yang J, Chang S, Hemati N, Richardson BC. Mechanisms of drug-induced lupus. II. T Cells overexpressing LFA-1 cause a lupus-like disease in syngeneic mice. Journal of Clinical Investigation 1996; 97:2866-2871.

26. Mo RR, Eisenbraun JK, Sonstein J, Craig RA, Curtis JL, Stoolman LM, Yung RL. CD49d overexpression and T cell autoimmunity. J Immunol 2003; 171:745-753.

27. Quddus J, Johnson KJ, Gavalchin J, Amento EP, Warren JS, Chrisp C, Yung RL, Richardson BC. Treating activated CD4+ $\mathrm{T}$ cells with either of two distinct DNA methyltransferase inhibitors, 5-azacytidine or procainamide, is sufficient to induce a lupus-like disease in syngeneic mice. J Clin Invest 1993; 92:38-53.

28. Yung R, Kaplan M, Ray D, Schneider K, Mo RR, Johnson K, Richardson B. Autoreactive murine Th1 and Th2 cells kill syngeneic macrophages and induce autoantibodies. Lupus 2001; 10:539-546.

29. Yung RL, Quddus J, Chrisp CE, Johnson KJ, Richardson BC. Mechanisms of drug-induced lupus. I. Cloned Th2 cells modified with DNA methylation inhibitors in vitro cause autoimmunity in vivo. J Immunol 1995; 154:3025-3035.

30. Yung R, Williams R, Johnson K, Stoolman L, Chang S, Richardson B. Mechanisms of drug-induced lupus III. Gender specific differences in splenic T cell homing explain increased disease severity in female mice. Arthritis Rheum 1997; 40:1334-1343.

31. Yung R, Chang S, Hemati N, Johnson K, Richardson B. Mechanisms of drug-induced lupus IV. Comparison of procainamide and hydralazine with analogs in vitro and in vivo. Arthritis Rheum 1997; 40:1436-1443.

32. Kaplan MJ, Ray D, Mo RR, Yung RL, Richardson BC. TRAIL (APO2 ligand) and TWEAK (Apo3 ligand) mediate CD4+ T cell killing of antigen-presenting macrophages. $J$ Immunol 2000; 164:2897-2904. 
33. Matsumoto G, Omi Y, Lee U, Nishimura T, Shindo J, Penninger JM. Adhesion mediated by LFA-1 is required for efficient IL-12-induced NK and NKT cell cytotoxicity. Eur J Immunol 2000; 30:3723-3731.

34. Poggi A, Carosio R, Spaggiari GM, Fortis C, Tambussi G, Dell'Antonio G, Dal Cin E, Rubartelli A, Zocchi MR. NK cell activation by dendritic cells is dependent on LFA-1mediated induction of calcium-calmodulin kinase II: inhibition by HIV-1 Tat C-terminal domain. J Immunol 2002; 168:95-101.

35. Wang P, Malkovsky M. Different roles of the CD2 and LFA-1 T-cell co-receptors for regulating cytotoxic, proliferative, and cytokine responses of human $\mathrm{V}$ gamma 9/V delta 2 T cells. Mol Med 2000; 6:196-207.

36. Huang GT, Zhang X, Park NH. Increased ICAM-1 expression in transformed human oral epithelial cells: molecular mechanism and functional role in peripheral blood mononuclear cell adhesion and lymphokine-activatedkiller cell cytotoxicity. Int J Oncol 2000; 17:479-486.

37. Kaplan MJ, Beretta-Hanash L, Yung R, Richardson BC. LFA-1 overexpression causes autoreactivity by overstabilizing low affinity TCR-Ia interactions. Immunol Invest 2000; 29:427-442.

38. Murphy HS, Sun Q, Murphy BA, Mo RR, Huo J, Chen J, Adams M, Chensue, SW, Richardson BC, Yung RL. Tissue Specific Effect of Estradiol on Endothelial Cell-Dependent Lymphocyte Recruitment (submitted).

39. Yung RL, Richardson BC. Drug-induced Rheumatic Syndromes. Bull Rheum Dis 2002; 51(4):1-5. 
TABLE AND FIGURES

\begin{tabular}{l} 
Questions Asked \\
\hline Can non-transformed T cells be \\
made to over-express cell surface \\
integrins? \\
Does integrin overexpression \\
induce T cell autoreactive \\
proliferation? \\
Does integrin overexpression \\
induce T cell cytotoxicity? \\
Is the integrin-induced \\
autoreactive proliferation due to \\
increased costimulatory signal or \\
overstabilization of TCR-MHC \\
class II interaction? \\
Does integrin overexpression \\
induce in vivo autoimmunity?
\end{tabular}
induce in vivo autoimmunity?

Does $\mathrm{T}$ cell splenic homing play a role in the induction of autoimmunity in this model?

Is the lack of the ability of CD49d overexpressing $\mathrm{T}$ cells to induce in vivo disease secondary to poor $\mathrm{T}$ cell adhesion function?

Can the lack of in vivo disease in mice receiving the CD49d transfectants be explained by differential splenic homing?

What is the role of gender in this autoimmunity model?

Does gender or estrogen affect $\mathrm{T}$ cell splenic homing?

\section{Experimental Techniques}

Drug-treatments with DNA

hypomethylating agents; flow cytometry, 2D-protein gel; electroporation; Southern blots

$\mathrm{T}$ cell proliferation assay

T cell cytotoxicity assay; electron microscopy

Western blots; calcium flux; TCR expression by flow cytometry in the presence of blocking antibodies

$\mathrm{T}$ cell adoptive transfer; ELISAs for autoantibody measurements; urinalyses; $\mathrm{H} \& \mathrm{E}$, immunofluorescence staining of tissues

Adoptive transfer of $\mathrm{T}$ cells into control and splenectomized mice

Static and flow adhesion assays

T cell trafficking experiments using control and transfected $\mathrm{T}$ cells labeled with $\mathrm{Cr}^{51}$ or cell tracker dyes

Adoptive transfer of 'T cells into control and castrated male and female mice

T cell trafficking experiments using male, female, castrated female mice with/without hormone supplementation

\section{Summary of Results}

Hypomethylated T cells over-express LFA-1. T cells transfected with CD11a or CD18 overexpress cell surface LFA1. D10 cells transfected with CD49d over-express CD49d/CD29

Both LFA-1 and CD49d overexpression cause T cells to proliferate in response to subthreshold amount of antigen in the presence of antigen presenting cells. Integrin overexpressing $\mathrm{T}$ cells lose the requirement for antigen to proliferate, and will response to MHC Class II molecules alone

LFA-1-overexpressing T cells will kill syngeneic macrophages by apoptosis without antigen. In contrast, CD49d overexpressing $\mathrm{T}$ cells are not cytotoxic

T cell LFA-1 and CD49d overexpression are associated with increased protein tyrosine phosphorylation despite minimal calcium flux. Successful TCR signaling occurs despite lowaffinity interactions

LFA-1 over-expressing T cells induced in vivo autoimmune disease (kidneys, lungs, liver and brain) in syngeneic mice. In contrast, CD49d overexpressing T cells are incapable of causing autoimmune disease

Splenectomized mice receiving the LFA-1 overexpressing T cells do not develop in vivo disease

CD49d overexpressing $\mathrm{T}$ cells demonstrated increase binding to endothelial cells in static adhesion assays. Increase binding of the CD49d transfectants to endothelial cells also occurs under low flow condition

CD49d-overexpressing T cells demonstrated increased splenic homing. The lack of in vivo disease therefore can not be explained by reduced splenic homing of the transfected cells

Oophorectomized female mice develop lower titer of autoantibodies and a less severe autoimmune disease

Female mice have 2-7 fold increased T cell splenic homing. Estrogen, but nor progesterone, increases T cell splenic homing in oophorectomized mice 
A

\section{A}

B C

$4.0 \mathrm{~kb}$

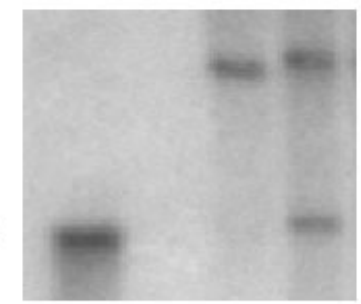

C

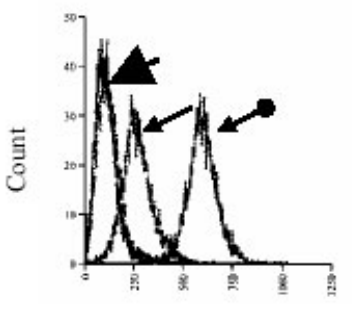

Channel
B
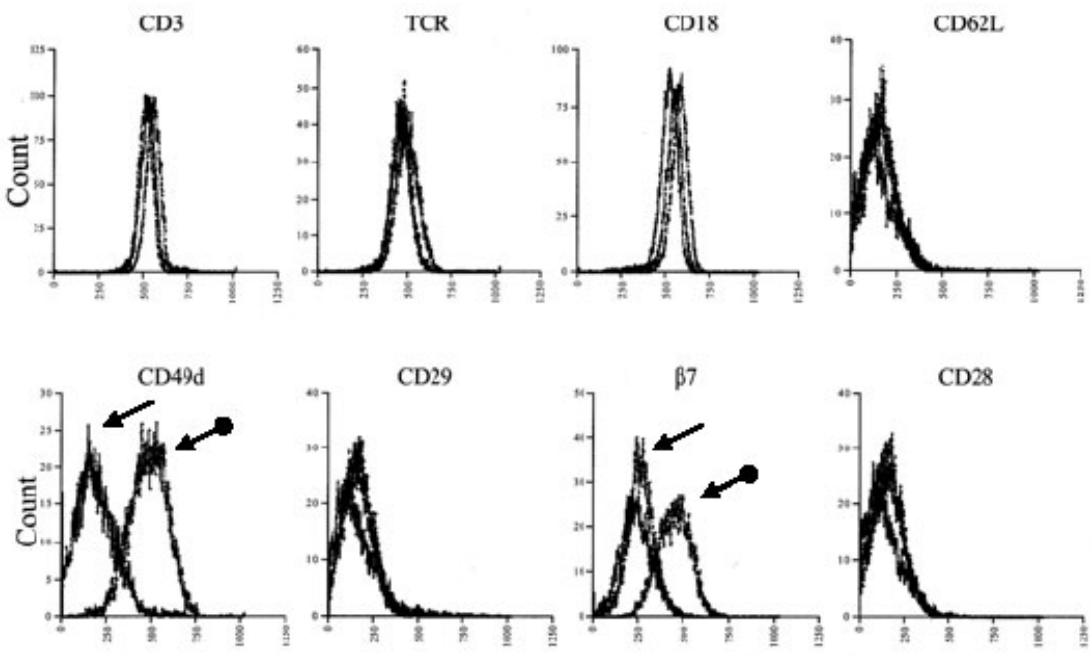

Channel

Fig. 1: A. Southern blot analysis of CD49d tranfected D10 cells. DNA from the pSub2-CD49d construct (a), untransfected D10 cells (b) and subcloned CD49d transfectants (c) were digested with Not1, fractionated by agarose gel electrophoresis, transferred to nylon filters and hybridized with the full length CD49d cDNA. The full length CD49d cDNA in the transfectant and the pSub2-CD49d construct is identified by the $4.0 \mathrm{~kb}$ band. B. CD49d transfectants (filled in circle with arrow pointing down and to the left) and untransfected D10 cells (arrow with small head) were stained with anti-CD3, -TCR, -CD18, -CD28, -CD29, - 37 , -CD49d and CD62L monoclonal antibodies. The $\mathrm{x}$-axis represents fluorescence intensity on an arbitrary scale, and the $\mathrm{y}$-axis represents cell number. C. CD49d transfectants and D10 cells stained with anti-CD49d/ $\beta 7$ antibodies (DATK32) or isotype-matched antibodies (arrow with large head). (Ref. 26; Copyright 2003. The American Association of Immunologists, Inc.).

A
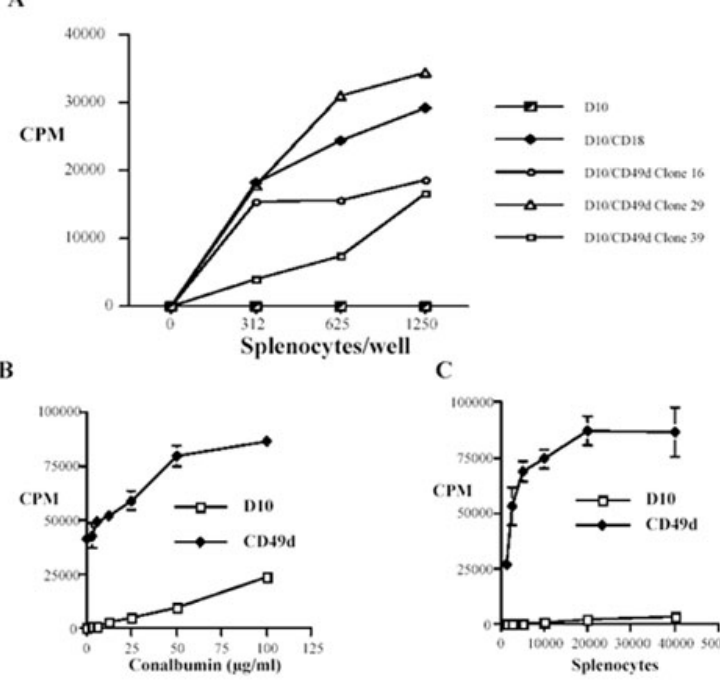

D

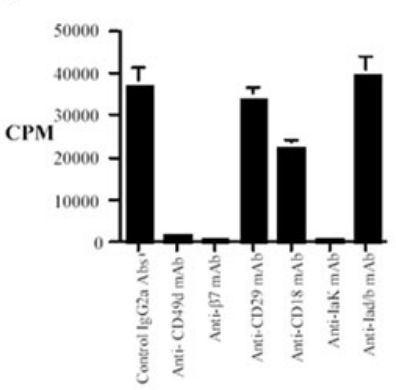

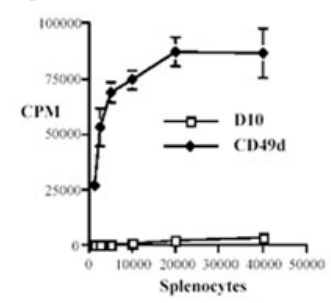

E

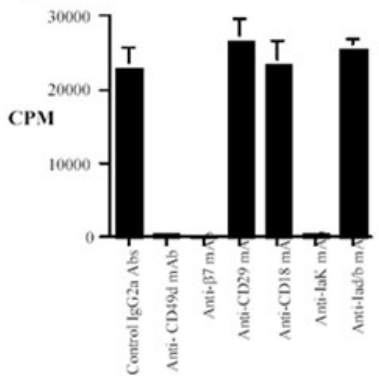

Fig. 2: CD49d overexpression causes autoreactivity in D10 cells. A. Autoreactive proliferation of CD18 transfectants, three different CD49d clones $(16,29,39)$ and untransfected D10 cells were compared. B. The antigen proliferation response of untransfected (D10) and CD49d transfected (Clone 29) D10 cells showing that the CD49d transfectants will proliferate in the presence of suboptimal concentrations of antigen (conalbumin). C. Autoreactive proliferation response of untransfected and CD49d transfected D10 cells in the presence of the indicated number of irradiated splenocytes. Effects of saturating amount $(10 \mu \mathrm{g} / \mathrm{ml}$ final concentration) of functional antibody blockade on the antigen (D) and autoreactive (E) proliferation responses of CD49d transfected D10 cells. The results represent the mean \pm SEM of quadruplicate determinations. (Ref. 26; Copyright 2003. The American Association of Immunologists, Inc.).

Biological Procedures Online • Vol. 5 No. 1 • October 24, $2003 \bullet$ www.biologicalprocedures.com 

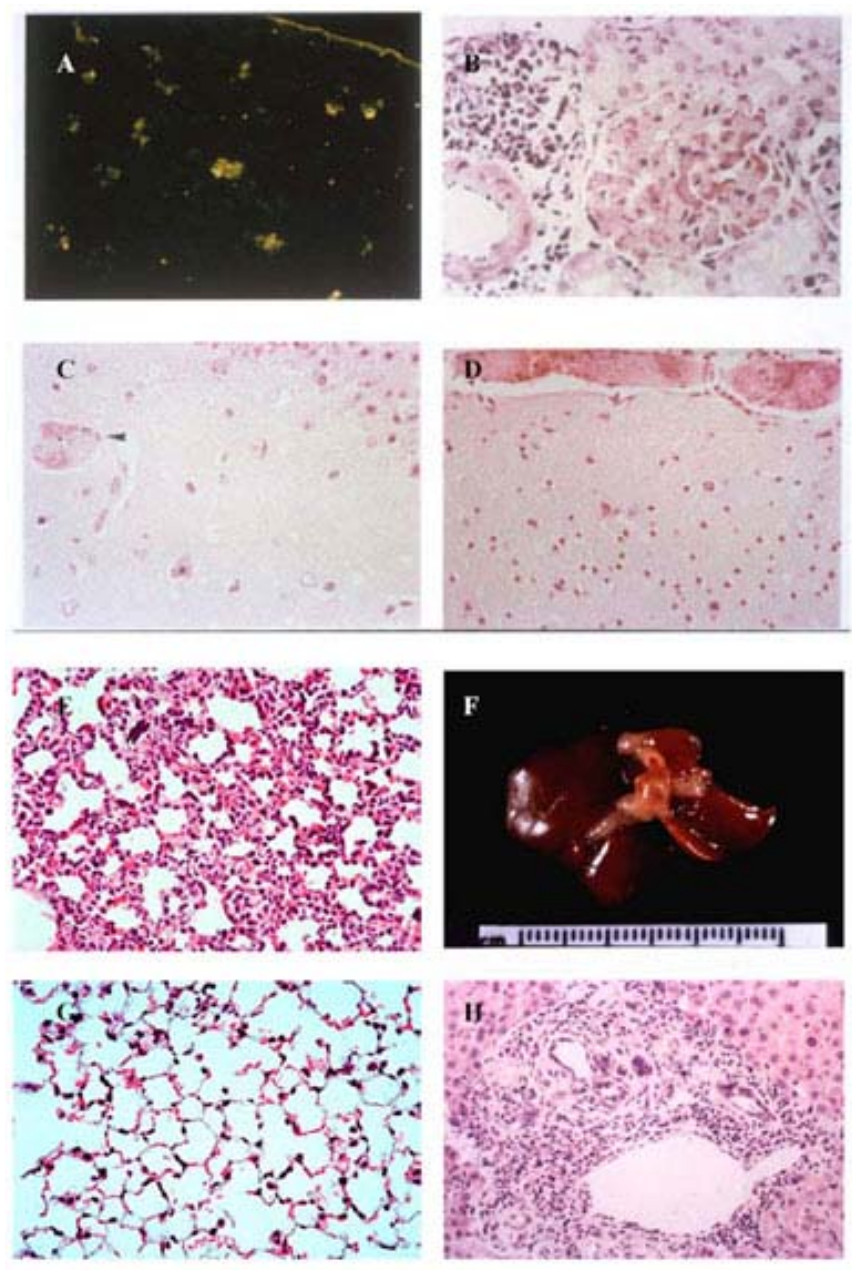

A

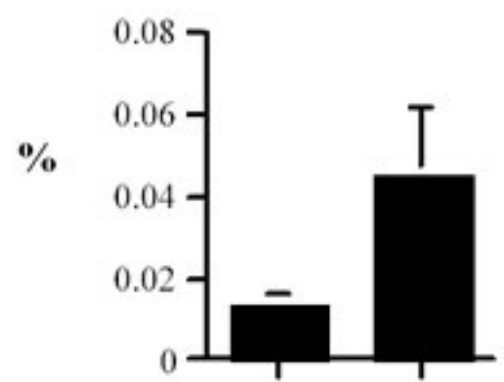

D10 D10/CD49d
Fig. 3: Representative tissue sections from mice receiving the LFA-1 overexpression D10 cells. A. IgG immunofluorescence staining of a kidney section showing IgG immune complex deposition in a mesangial pattern (X100). B. H\&E staining of kidney section showing severe glomerulonephritis and mononuclear cell infiltration (X230). C. Brain in an affected mice showing bland thrombosis in a small intracerebral vessel (X150). D. Brain section of an affected mouse showing menningeal vessel thrombosis (X150). E. Lung tissue showing severe pneumonitis (X200). F. Gross specimen of liver with bile duct dilatation and proliferation. G. Lung tissue of a control mouse with normal lung architecture (X200). H. H\&E staining of liver tissue showing periductal inflammatory cell infiltration (X200).

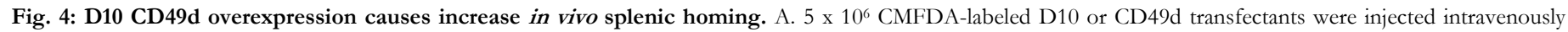

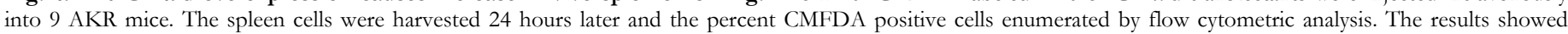

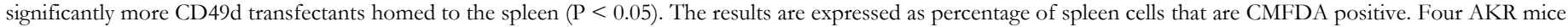

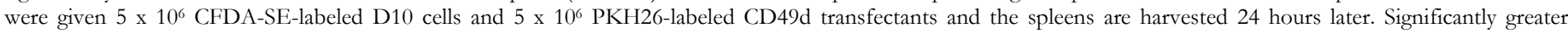

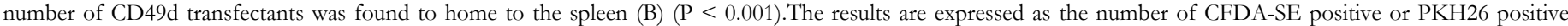
events per 100,000 events during the flow cytometric studies. (Reference 26; Copyright 2003. The American Association of Immunologists. Inc.). 